\title{
ORIGINAL ARTICLE Management of patients presenting with diarrhoea to a regional emergency department in KwaZulu-Natal: Call for clearer, more relevant guidance
}

S Kudsk-Iversen, BSc (Hons), MB ChB, Dip HIV Man (SA), DTM\&H; J P Gilbert, MB ChB, Dip PEC (SA), DTM\&H; A Azarath, Professional Nurse

Stanger Provincial Hospital, Stanger, KwaZulu-Natal, South Africa

Corresponding author: S Kudsk-Iversen (sorenki@gmail.com)

Background. HIV is prevalent throughout South Africa, and diarrhoea is a common presentation to the emergency department (ED) among both HIV-infected and -uninfected individuals.

Method. We audited the management of diarrhoea against standard guidelines in the ED of a regional hospital in KwaZulu-Natal. Patients presenting with diarrhoea as their chief complaint were eligible and data were collected prospectively.

Results. A total of 72 patients were included: 58 (81\%) of patients were HIV-positive with an average $\mathrm{CD}^{+}$count of 180 cells/ $\mu$ l. A total of 34 stool samples were sent for standard microscopy and culture (M\&C), among which 26 were positive ( $76 \%$ ). Forty-three patients $(60 \%)$ received antibiotics, 15 of whom had positive stool M\&C. In all cases, the final diagnosis was listed as acute gastroenteritis without further specification, and antibiotic use according to guidelines appeared inconsistent.

Conclusion. Based on this audit, we suggest that current guidelines are not clear concerning management of acute diarrhoea in HIVinfected individuals, and that the lack of clear management strategies is likely to affect patient safety and increase antibiotic resistance.

S Afr J HIV Med 2014;15(3):102-103. DOI:10.7196/SAJHIVMED.1082

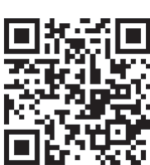

HIV and related conditions are common causes of hospital presentations across South Africa (SA), and diarrhoea is a common presentation to the emergency department (ED) in highprevalence areas. ${ }^{[1,2]}$ A differential diagnosis of any HIV-seropositive patient presenting with diarrhoea will thus need to consider a wider variety of infectious pathogens as well as non-infectious causes. ${ }^{[3,4]}$

In SA, the Department of Health's Essential Medicines List (EDL) has a list of guidelines concerning diarrhoea. It states that acute diarrhoea with blood or mucus in the stool is suggestive of acute inflammatory colitis and may have an infective cause. Stool culture is advised and a course of antibiotics is recommended. HIV/AIDS is not considered in the acute diarrhoea guidelines, only in the subsequent discussion of opportunistic infections that cause chronic diarrhoea, i.e. diarrhoea lasting $>4$ weeks. ${ }^{[5]}$ With this background, we decided to audit the management of all types of diarrhoea against EDL guidelines in the ED of a provincial hospital in KwaZulu-Natal.

\section{Methods}

All patients presenting to the ED with diarrhoea as their chief complaint were eligible for inclusion. Data were collected prospectively, between February and April 2013, including demographic characteristics, HIV status, presenting symptoms, prescription of antibiotics, blood results, final management, and stool microscopy and culture (M\&C). We performed univariate analysis of clinical predictors of positive stool M\&C and admission, using Fisher's exact test to examine statistical significance.

\section{Results}

A total of 72 patients were included (Table 1). We used estimated glomerular filtration rate (eGFR) and white cell count (WCC) as proxy indicators for severity. We considered an eGFR of $<60 \mathrm{ml} / \mathrm{min} / 1.73 \mathrm{~m}^{2}$ to indicate renal impairment and a WCC of $>11 \times 10^{9} / 1$ to indicate leucocytosis. CD $4^{+}$counts were available for 28/58 HIV-seropositive patients.

A total of 34 stool samples were sent for M\&C. We considered the stool M\&C positive, i.e. demonstrating an infection in the bowel, if any bacteria had grown (the laboratory tested for Salmonella spp, Shigella and Campylobacter) or there were white cells and/or yeasts present. No specimen grew bacteria, but 26 were positive for white cells and/or yeasts.

Forty-three patients received antibiotics; Table 2 examines the use of antibiotics in relation to investigations and management. In all cases, a final diagnosis of acute gastroenteritis was made (no matter the duration), with no differentiation to suggest reason for choice or duration of antibiotic treatment.

\section{Discussion}

The majority of the patients included in our audit presented with acute-onset diarrhoea, which had a median duration of only 3 days. Upon presentation, the initial focus should be to resuscitate the patient with particular focus on fluid status, regardless of their HIV status. However, when considering the underlying condition, it is important to acknowledge the fact that most of the patients were severely immunocompromised. ${ }^{[3,4]}$

A large proportion of patients were prescribed antibiotics, and this appears unrelated to severity of disease or possibility of being admitted. This prescribing practice, factoring in that $84 \%$ 
were given only a single dose of antibiotics, puts the patient at risk of both undertreated infection and the development of a resistant organism. This is a very real possibility in a region with high HIV endemicity, as observed in other studies ${ }^{[6,7]}$ Furthermore, with HIV-positive patients being treated both prophylactically and more frequently with antimicrobial agents, the risks of resistance ${ }^{[8]}$ and antimicrobial-related colitis caused by Clostridium difficile $^{[2,9]}$ are further increased.

We found no correlation between positive stool microscopy and patient-reported symptoms of blood or mucus in the stool. There could be several reasons for this, and it would be worthwhile exploring this in more depth. In our audit, we requested stool M\&C from a single specimen, which is a significant limitation, as multiple investigations are more likely to find a causative organism. ${ }^{[10]}$ The feasibility of carrying out multiple investigations in the ED of a public hospital in a highly endemic area needs consideration. Algorithms for definitive diagnosis have been described, but require multiple investigations over multiple visits to a hospital with relatively advanced diagnostic facilities. ${ }^{[11]}$

\section{Table 1. Demographics of audit population $(\mathbf{N}=\mathbf{7 2})$}

\begin{tabular}{|c|c|}
\hline Admitted following presentation, $n(\%)$ & $32(44)$ \\
\hline Age (years), mean (range) & $39(12-81)$ \\
\hline Gender (female), $n(\%)$ & $41(57)$ \\
\hline Duration of diarrhoea (days), median (range) & $3(1-120)$ \\
\hline Acute (lasting $<28$ days), $n$ & 59 \\
\hline Chronic (lasting $\geq 28$ days), $n$ & 4 \\
\hline Duration unknown, $n$ & 9 \\
\hline HIV status (HIV-positive), $n$ (\%) & $58(81)$ \\
\hline $\mathrm{CD}^{+}$count $($cells $/ \mu \mathrm{l})$, median (range) & $137(6-480)$ \\
\hline eGFR $\left(\mathrm{ml} / \mathrm{min} / 1.73 \mathrm{~m}^{2}\right)$, mean (range) & $91(9-282)$ \\
\hline$<60, n$ & 21 \\
\hline$\geq 60, n$ & 48 \\
\hline WCC $\left(\times 10^{9} / 1\right)$, mean (range) & $9.25(1.54-26.6)$ \\
\hline$<11, n$ & 53 \\
\hline$\geq 11, n$ & 15 \\
\hline
\end{tabular}

\section{Conclusion}

This audit found that the population coming through the ED with diarrhoeal symptoms was predominantly HIV-positive with a low CD4 $4^{+}$ count, and the signs and symptoms largely suggested acute episodes of infective diarrhoea leading to renal dysfunction and leucocytosis. Nevertheless, we found that the management was for the most part inconsistent and could put the patient at risk of both antibiotic resistance, or (as is the case for the use of ciprofloxacin) antibioticrelated C. difficile colitis. Although the EDL guidelines offer guidance for antibiotic prescribing, clearer prescribing and management guidelines for acute diarrhoea in HIV-positive individuals, particularly in cases of AIDS, are needed.

\section{References}

1. Kelly P, Todd J, Sianongo S, et al. Susceptibility to intestinal infection and diarrhoea in Zambian adults in relation to HIV status and CD4 count. BMC Gastroenterol 2009;9:7. [http://dx.doi.org/10.1186/1471-230X-9-7]

2. Venkat A, Piontkowsky DM, Cooney RR, Srivastava AK, Suares GA, Heidelberger CP. Care of the HIV-positive patient in the emergency department in the era of highly active antiretroviral therapy. Ann Emerg Med 2008;52(3):274-285. [http://dx.doi. org/10.1016/j.annemergmed.2008.01.324]

3. Beeching N, Jones R, Gazzard B. Gastrointestinal opportunistic infections. HIV Med 2011;12(Suppl 2):43-54. [http://dx.doi.org/10.1111/j.1468-1293.2011.00944_5.x]

4. Vyas N, Pathan N, Aziz A. Enteric pathogens in HIV-positive patients with diarrhoea and their correlation with CD4+ T-lymphocyte counts. Trop Parasitol 2012;2(1):29 34. [http://dx.doi.org/10.4103/2229-5070.97236]

5. Department of Health South Africa. Standard Treatment Guidelines and Essential Medicines List For South Africa, Hospital Level Adults, 2012 Edition. Pretoria: Department of Health, 2012.

6. Rowe JS, Shah SS, Motlhagodi S, et al. An epidemiologic review of enteropathogens in Gaborone, Botswana: Shifting patterns of resistance in an HIV endemic region. Myer L, ed. PLoS ONE 2010;5(6):e10924. [http://dx.doi.org/10.1371/journal. pone.0010924]

7. Samie A, Mashao MB, Bessong PO, NKgau TF, Momba MNB, Obi CL. Diversity and antibiograms of bacterial organisms isolated from samples of household drinkingwater consumed by HIV-positive individuals in rural settings, South Africa. J Health Popul Nutr 2012;30(3):241-249.

8. Byarugaba DK. A view on antimicrobial resistance in developing countries and responsible risk factors. Int J Antimicrob Agents 2004;24(2):105-110. [http://dx.doi. org/10.1016/j.ijantimicag.2004.02.015]

9. McCusker ME, Harris AD, Perencevich E, Roghmann MC. Fluoroquinolone use and Clostridium difficile-associated diarrhea. Emerg Infect Dis 2003;9(6):730-733 [http://dx.doi.org/10.3201/eid0906.020385]

10. Oude Munnink BB, Canuti M, Deijs M, et al. Unexplained diarrhoea in HIV-1 infected individuals. BMC Infect Dis 2014;14(1):22. [http://dx.doi.org/10.1186/14712334-14-22]

11. Feasey NA, Healey P, Gordon MA. Review article: The aetiology, investigation and management of diarrhoea in the HIV-positive patient. Aliment Pharmacol Ther 2011;34(6):587-603. [http://dx.doi.org/10.1111/j.1365-2036.2011.04781.x]

\section{Table 2. Use of antibiotics in all cases}

\begin{tabular}{|c|c|c|c|}
\hline & Antibiotics given $(N=43)$ & Antibiotics not given $(N=29)$ & $p$-value \\
\hline Stool M\&C, $n$ & & & 1.000 \\
\hline Positive & 15 & 10 & \\
\hline Negative & 5 & 3 & \\
\hline Final outcome, $n$ & & & 0.439 \\
\hline Discharged & 18 & 14 & \\
\hline Admitted & 21 & 10 & \\
\hline \multicolumn{4}{|l|}{ Severity, $n$} \\
\hline Leucocytosis and renal impairment $(n=5)$ & 4 & 1 & $0.633^{*}$ \\
\hline Only leucocytosis $(n=10)$ & 5 & 5 & $0.723^{\star}$ \\
\hline Only renal impairment $(n=16)$ & 11 & 5 & $0.758^{\star}$ \\
\hline None of the above $(n=37)$ & 22 & 15 & \\
\hline Only stat dose given, $n$ (\%) & $36(84)$ & - & \\
\hline Antibiotics prescribed, as advised by the EDL guidelines, $n$ (\%) & $25(58)$ & - & \\
\hline
\end{tabular}

